\title{
Air jet cooling of brake discs.
}

By

\author{
O.F.P.Lyons, D.B.Murray and A.A.Torrance
}

Dept. of Mechanical \& Manufacturing Engineering, Trinity College, Dublin 2, IRELAND

\begin{abstract}
This paper reports on an investigation of a novel approach to the cooling of brake discs, based on the application of impinging air jets. This has the capacity to enhance the heat transfer coefficients at the disc surface quite considerably without affecting the disc design, so that the disc construction may then be optimized without reference to heat transfer. Using a purpose built test-rig, disc temperature histories were recorded using IR thermography for varying jet air flow rates, angle of impingement, dimensionless distance from the brake disc and rotational speed. As well as comparing cooling effectiveness for different test parameters, convective heat transfer coefficients were calculated from the transient temperature data and were used as boundary conditions for a finite element model of the process. The results obtained from this investigation suggest that the higher convection coefficients achieved with jet cooling will not only reduce the maximum temperature in the braking cycle but will reduce thermal gradients, since heat will be removed faster from hotter parts of the disc. Jet cooling should therefore be effective to reduce the risk of hot spot formation and associated disc distortion.
\end{abstract}

\section{INTRODUCTION}

Disc brakes are required to transform large amounts of kinetic energy into heat at the contact between the disc and pad. The resulting temperature distribution at the friction 
interface can be quite complex, and directly affects braking performance. It has been investigated by several researchers over many years [1-6], who have shown how high temperatures can cause a fall in friction coefficient, or fade, and increased wear of both discs and pads. Both fade and increased wear are affected by local thermal distortions of the disc, which can lead to hot spots [7]. These hot spots are amongst the most dangerous phenomena in brakes, since they are associated with high thermal gradients. The consequent stress fields can lead to low cycle fatigue of the discs, cracking, and even catastrophic failure [8]. Local thermal distortion also concentrates the braking effort over a small fraction of the pad area, which increases local flash temperatures with a resulting increase in wear and fall in friction.

If there is insufficient time for the disc to cool between one brake application and the next, the maximum temperature will rise, exacerbating the above problems. If the overall temperature is high enough, the brake fluid may boil in the caliper cylinders, leading to "fluid fade", and a potentially dangerous reduction in braking effort. For this reason, brake discs are often designed with slots or holes to create turbulence as they rotate, and thus to enhance convective heat transfer to the air [8,_9]. The design constraints on the discs make it difficult to optimize every aspect of their design simultaneously, since it is desirable to optimize the weight and stiffness of the discs as well as their heat capacity and heat transfer capability, which leads to conflicting design requirements.

Impinging jets are known as a method of achieving particularly high heat transfer coefficients and are therefore employed in a broad range of engineering applications. Although liquid jet cooling yields higher heat transfer coefficients, air jet cooling can be very effective and clearly has merits in terms of the simplicity of the cooling system. Thus, ElSheikh and Garimella [10] investigated the air impingement cooling of heat sinks for electronics, Roger, Buck and Muller-Steinhagen [11] investigated the jet impingement 
cooling of a high temperature solar thermal receiver and O'Donovan et al. [12] and Babic et al. [13] used air and mist jet impingement respectively for the cooling of a grinding process.

In order to interpret the results from jet impingement cooling, it is necessary to determine the convective heat transfer coefficients. One common technique for determination of convection coefficients from surface temperature measurements involves a step change in temperature of either the fluid or the test specimen; thus the necessity for electrical surface heating, and the associated geometric constraints, is overcome. Most studies based on this technique have involved the instantaneous introduction of a heated flow field to the specimen [14-16]. However, in the study of Martinez-Botas et al. [17] the test section is heated and then introduced to an ambient temperature flow. In both cases the rate of heat transfer is found by measuring the surface temperature as a function of time. Although most previous investigations have used liquid crystal thermography for these measurements, Ekkad et al. [16] developed an approach based on IR thermal imaging, which determines both heat transfer coefficient and film effectiveness (non-dimensional adiabatic wall temperature) in a film cooling application. Solution of the transient conduction equation with a semi-infinite solid assumption then yields the convective heat transfer coefficient.

In this paper, a novel approach to the cooling of brake discs is investigated. It relies on applying a well-proven method of air cooling - impinging air jets - to the surface of the disc. This has the capacity to enhance the heat transfer coefficients at the disc surface quite considerably, independently of disc design, so that the disc construction may be optimized for strength, weight and stiffness. It should also be possible to achieve much higher heat transfer coefficients than can be attained with current techniques, thereby reducing the thermal problems described above. The main additional requirements are a supply of compressed air onboard the vehicle, and a suitable arrangement of nozzles to deliver it to the discs during braking. In heavy vehicles, such as trucks, coaches and rail vehicles, this should pose no 
problem, since compressed air is usually available as standard. For smaller vehicles, though, the expense of a compressor could prove an impediment.

\section{EXPERIMENTAL TESTING}

\subsection{Experimental Rig and Instrumentation}

In order to study the heat transfer from a brake disc in isolation from tribological effects, a special apparatus was designed and built. It is shown in figures $1 \mathrm{a}$ and $1 \mathrm{~b}$.

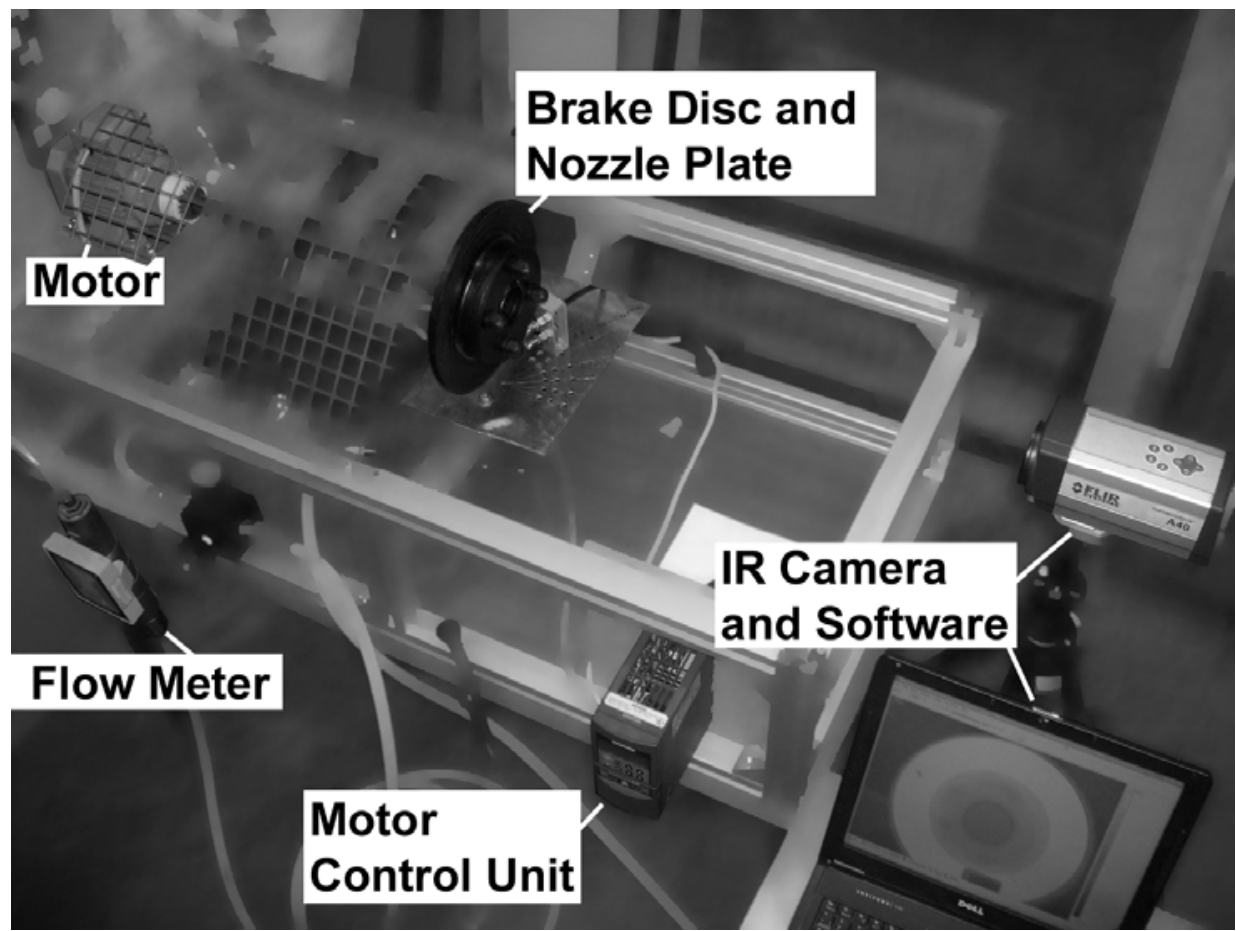

Figure 1a. Experimental apparatus. 


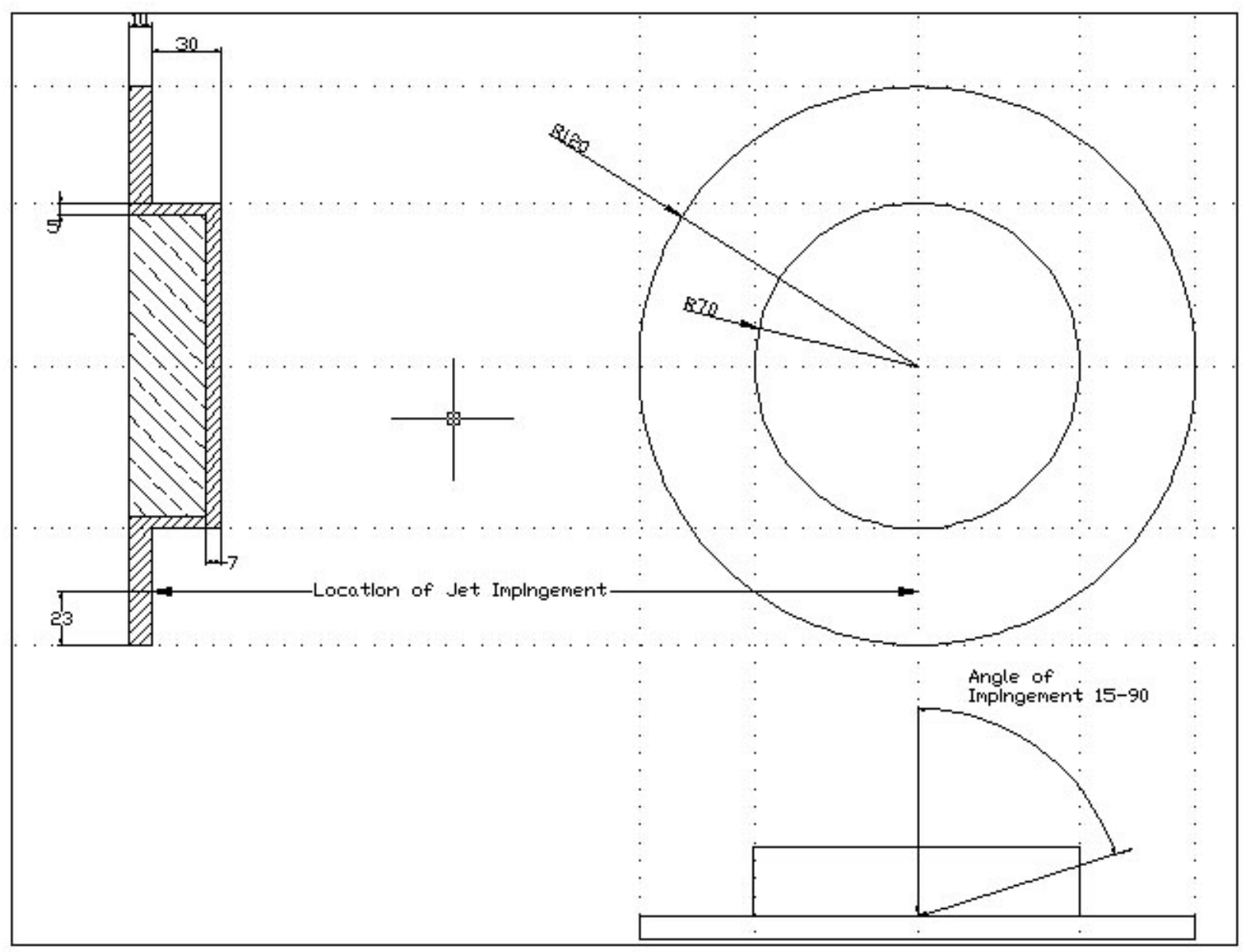

Figure 1b. Schematic of Brake Disc Impingment

A standard automotive cast iron brake disc from a Nissan Micra (flange diameter $=238 \mathrm{~mm}$, hub diameter $=140 \mathrm{~mm}$, flange thickness $=9 \mathrm{~mm}$ ) was mounted on a shaft, running on two ball bearings, and driven through a coupling by a 3 phase AC motor. The speed of the motor was controlled by a Siemens inverter fixed to the frame of the apparatus. A nozzle plate was mounted on the frame to allow up to four Silvent BS1001 stainless steel Laval nozzles to be directed towards the disc in various orientations. The jets impinged at $23 \mathrm{~mm}$ from the edge of the brake disc. However, for all the tests reported here, two nozzles were used, one on each side. The nozzles were aligned so as to impinge on a point on the rotor centre line and the fixing method allowed the angle of impingement, defined as the angle subtended between the nozzle and the disc face, and the dimensionless distance from the brake disc, $H / D$, to be 
varied. These nozzles have a central orifice surrounded by six slots. The effective hydraulic diameter is $5 \mathrm{~mm}$, and the effective throat of the nozzle is downstream of the orifice. Air was supplied to these nozzles from the building's 6 bar compressed air supply; the flow rate was controlled and measured by a Bosch 0821 pressure regulator and a Platon GMT metal tube flow meter respectively. The maximum flow velocity in the jet is supersonic when the supply pressure is over 2 Bar.

IR thermography was used to record the surface temperature distribution on the brake disc using a FLIR ThermaCam A40 thermal imaging camera. The disc was painted with black heat resisting paint with an emissivity of 0.95 . This increases the signal to noise ratio, and cuts down reflections, which might otherwise disturb the readings, increasing the accuracy of the temperature measurements. The thermal imaging camera was calibrated against a precalibrated K-type thermocouple affixed to the disc and tests were conducted to confirm repeatability and to eliminate the influence of variations in the ambient temperature. The camera records temperatures at 320 by 240 pixels in each image and images were recorded at $5 \mathrm{~s}$ intervals for test periods of $250 \mathrm{~s}$. The resolution of the infra red camera is $0.1{ }^{0} \mathrm{C}$ in the range setting $\left(0{ }^{0} \mathrm{C}\right.$ to $\left.500{ }^{\circ} \mathrm{C}\right)$ used for these tests and the temperatures reported represent an average across a central (10mm wide) band of the flange. Data transfer was through a firewire 1394 interface to a laptop computer; the ThermaCAM imaging software was used to convert each image to a MATLAB array and further processing took place in MATLAB.

A model brake disc of low thermal conductivity is required to determine convection coefficients by use of the semi-infinite solid solution to the transient conduction equation. This is because, for a given model thickness, the material thermal diffusivity and allowable test times are constrained by the validity of the semi-infinite assumption, Schultz \& Jones [18], this details one dimensional conduction. Thus, a Perspex replica of the actual brake disc 
has been constructed; this yields an allowable test period of $90 \mathrm{~s}$. This analysis follows the procedure proposed by Ekkad et al. [16], in which the difference between the temperature of the cooling jet and the ambient temperature is accounted for by the use of a cooling effectiveness parameter, $\eta$. The heat transfer coefficient, $h$, is determined from equation (1), in which $\alpha$ represents the thermal diffusivity, $k$ the thermal conductivity and erfc is the complimentary Gaussian error function; subscripts $s, i, c$ and $\infty$ refer to surface, initial, jet and ambient temperatures respectively.

$$
d T=\frac{\left(T_{s}-T_{0}\right)}{\left(T_{\infty}-T_{0}\right)-\eta\left(T_{\infty}-T_{c}\right)}=1-\exp \left(\frac{h^{2} \alpha t}{k^{2}}\right) \operatorname{erfc}\left(\frac{h \sqrt{\alpha t}}{k}\right)
$$

\subsection{Test Procedure}

In the first series of tests, the flange of the brake disc was heated to $160{ }^{0} \mathrm{C}$ with a butane torch, whilst being rotated at $100 \mathrm{rev} / \mathrm{min}$. The objective of this process was to heat the brake disc to a high, uniform temperature so that the efficacy of different cooling settings could be investigated. The IR camera was used to monitor the temperature uniformity across the brake disc. Figure 2 shows a typical reading of the disc just after heating had ceased. The temperature varies little circumferentially, but is about $15{ }^{0} \mathrm{C}$ lower at the edges of the flange than at mid diameter. Following this pre-heating process, the speed of the disc was then increased to a specific test setting (ranging from 500 to $1500 \mathrm{rev} / \mathrm{min}$ ) for the jet cooling tests. The nozzle to disc spacing was set to $15 \mathrm{~mm}, 30 \mathrm{~mm}$ or $50 \mathrm{~mm}$, corresponding to H/D ratios of 3, 6 and 10 respectively and for each of these settings tests were conducted for angles of impingement of $15^{\circ}, 45^{\circ}, 75^{\circ}$ and $90^{\circ}$. The total air flow rate, in standard litres/s 
through both jets, was set at $4.53,7.85,10.96$ or 14.2 litres/s. The temperature of the disc as it cooled was monitored with the infra red camera for the test duration of $250 \mathrm{~s}$.

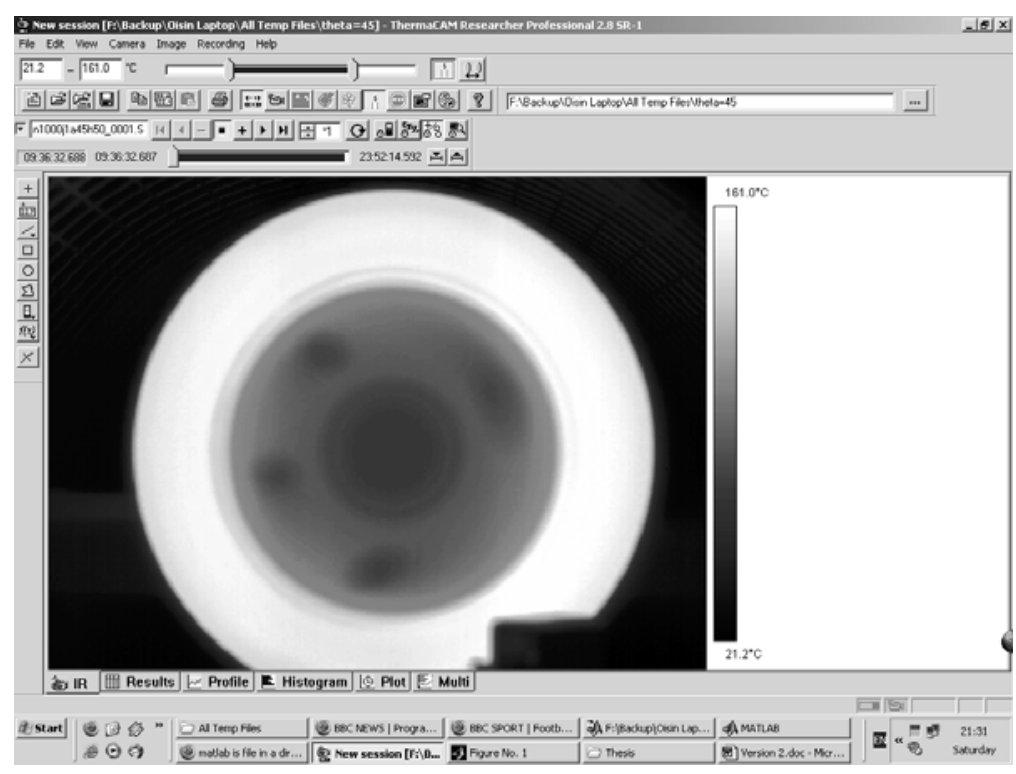

Figure 2. IR camera image of the brake disc at the end of a heating cycle.

A second series of tests was run with the Perspex replica of the brake disc, also painted black. In these tests, the disc was heated with a hot air gun to a uniform temperature of $40{ }^{\circ} \mathrm{C}$. In all tests, jet flow is in the same direction as the rotation of the disk. Initial tests had shown this to obtain higher cooling rates than contra flow. Uniformity of the surface temperature was determined from thermal imaging whereas heat penetration within the Perspex was verified by a fine gauge thermocouple located within the flange. Once a stable and uniform temperature was established, cooling tests were conducted as before. The objective here was to obtain transient surface temperature data for determination of the convective heat transfer coefficients, as described in section 2.1.

\section{RESULTS}




\subsection{Cooling curves for the brake disc}

\section{Baseline tests without jet cooling}

The first set of tests investigated the effect of disc rotational speed on the cooling curves. No jets were used so as to provide a baseline from which subsequent results could be assessed. Six different speeds were used, giving the curves shown in figure 3 . The effectiveness of cooling can be assessed by the time taken for the surface of the disc to lose half its initial temperature excess $\left(t_{1 / 2}\right)$, i.e. the time corresponding to $T_{s}-T_{\infty}=0.5\left(T_{\text {initial }}-T_{\infty}\right)$. At $500 \mathrm{rev} / \mathrm{min}$, it takes $341 \mathrm{~s}$ for this level of cooling to take place, whilst at $1500 \mathrm{rev} / \mathrm{min}$ the corresponding time is $193 \mathrm{~s}$. For this configuration, convective cooling results only from the relative motion between the rotating disc and the stationary air; thus disc speed has a significant effect on cooling time. However, when these tests were repeated with one of the least effective jet cooling configurations (impingement angle of $15^{\circ}$, dimensionless disc to jet spacing, $H / D$, of 10 and flow rate of $7.851 / \mathrm{s}$ ), the cooling curves at different disc speeds showed much less variation, giving $t_{1 / 2}=108 \mathrm{~s}$ at $500 \mathrm{rev} / \mathrm{min}$ and $t_{1 / 2}=87 \mathrm{~s}$ at $1500 \mathrm{rev} / \mathrm{min}$. As the effect of disc speed on cooling was small compared to that of the jet, a speed of 1500 $\mathrm{rev} / \mathrm{min}$ was used in all subsequent tests.

\section{Jet cooling tests}

In the next series of tests, the effects of varying flow rate and H/D were investigated for an impingement angle of $90^{\circ}$ and a disc rotational speed of $1500 \mathrm{rev} / \mathrm{min}$. The results are summarised in figure 4 . For comparison, without the jets, $t_{1 / 2}=193 \mathrm{~s}$. At the highest flow rate $(14.2 \mathrm{l} / \mathrm{s})$, the jets cool the disc 3.3 times faster than it cools without jets. What is just as interesting is that moving the jets closer to the disc achieves nearly as much cooling at the lowest air flow rate: with $H / D=3$, and a flow rate of $4.531 / \mathrm{s}$, the cooling is still 2.6 times 
faster than with no jets. This could have important implications for the design of practical cooling systems for brakes where a special supply of compressed air is required.

A third series of tests was run to investigate the effect of impingement angle on the cooling. as discussed by [19]. Figure 5 shows how the value of $t_{1 / 2}$ changes with flow rate and angle, for a dimensionless disc to jet spacing of $\mathrm{H} / \mathrm{D}=10$. Two points may merit further investigation: firstly, the minimum evident in $t_{1 / 2}$ at $75^{\circ}$ for the two lower flow rates, indicative of an optimal cooling angle. This is broadly similar to the angle obtained by Roy and Patel [20]. Secondly, that at an impingement angle of $15^{\circ}, t_{1 / 2}$ seems higher, and cooling less effective, as the flow rate rises to its maximum. Once again, it can be seen how, by carefully selecting the design parameters, cooling can be optimized for low flow rates, so that results nearly as good as those at much higher flow rates can be achieved.

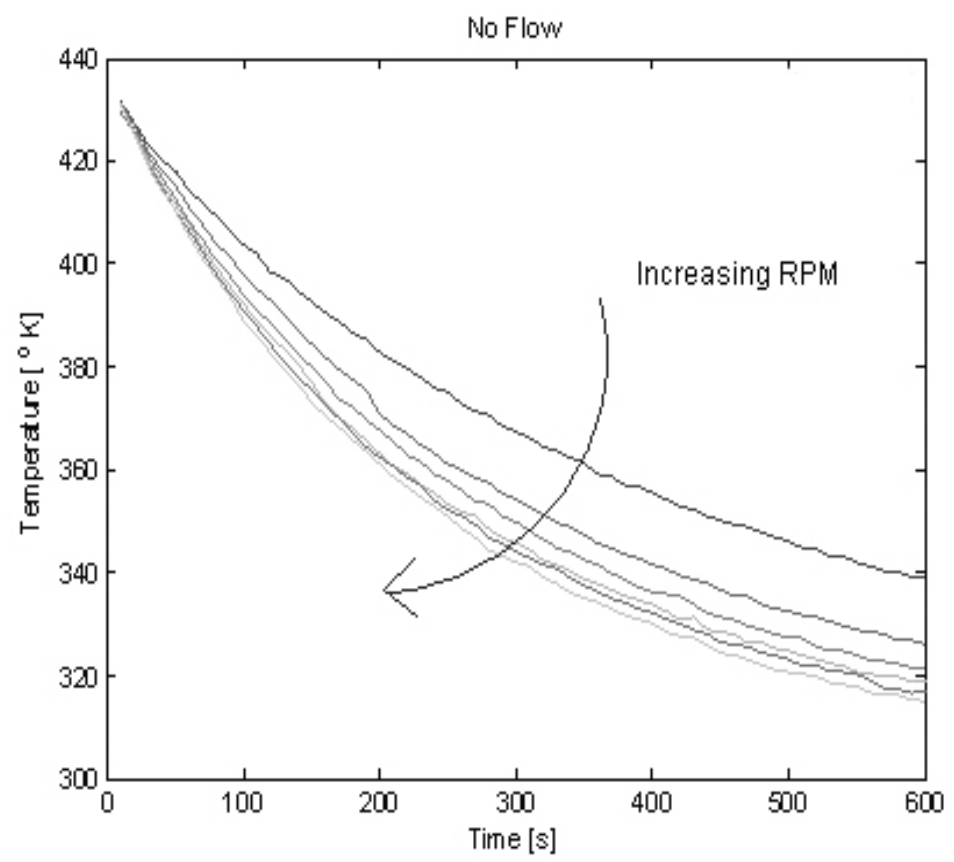

Figure 3. Cooling curves with no jets: the effect of rotational speed.

Two more series of tests were run at $H / D=6$ and $H / D=3$ to find how impingement angle influenced cooling when the jet was set closer to the disc. Both series were conducted 
at the lowest flow rate $(4.53 \mathrm{l} / \mathrm{s})$, and both showed that when the jet was moved closer to the disc, impingement angle had very little effect on the cooling. Thus impingement angle only seems to be a significant design consideration if the jet is far enough away from the disc.

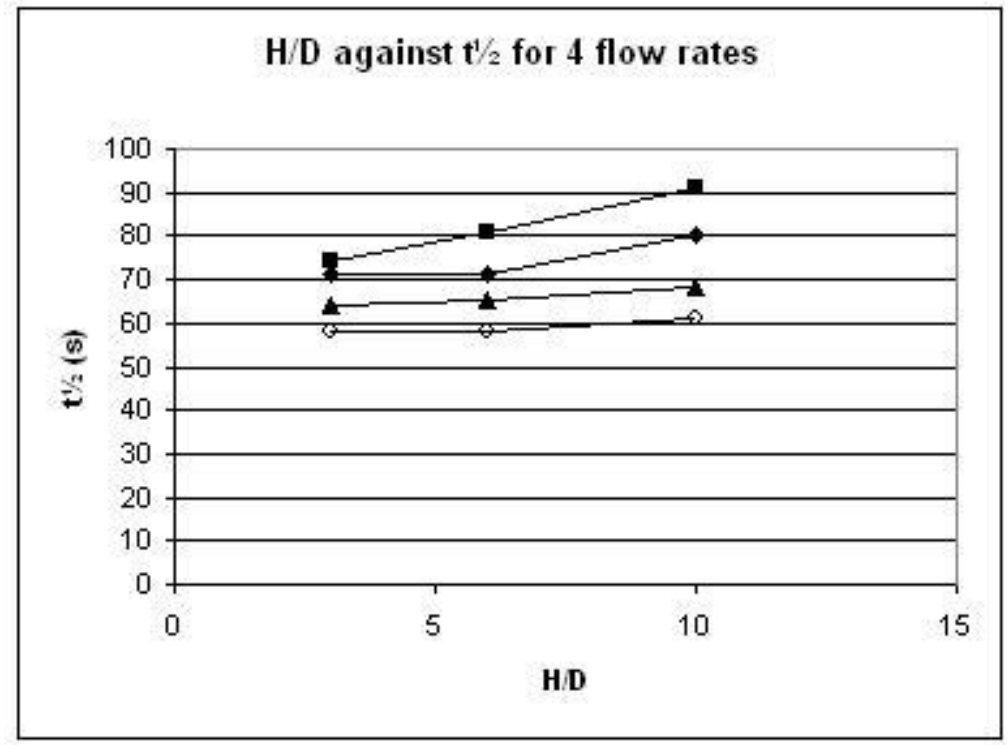

Figure 4. Effectiveness of cooling $\left(t_{1 / 2}\right)$ as a function of $H / D$ and flow rate.
$4.531 / \mathrm{s}$
$\checkmark 7.851 / \mathrm{s}$
$\Delta 10.961 / \mathrm{s} \quad \diamond 14.21 / \mathrm{s}$

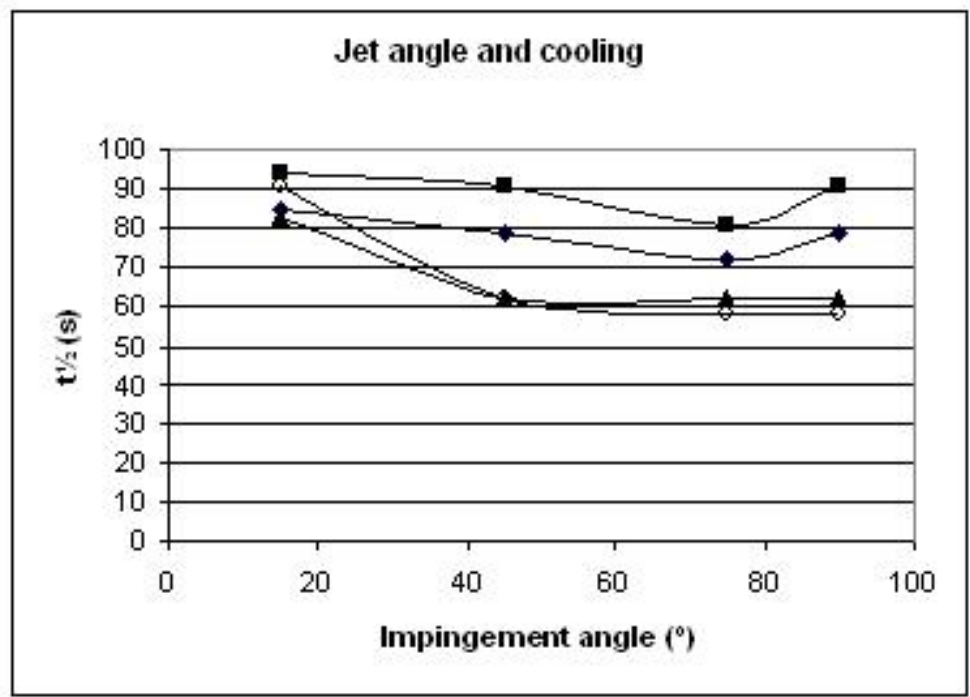


Figure 5. Effectiveness of cooling $\left(t_{t / 2}\right)$ as a function of impingement angle and flow rate $(H / D$

$$
=10) \text {. }
$$

- $4.531 / \mathrm{s} \quad 7.851 / \mathrm{s} \quad \boldsymbol{\Delta} 10.961 / \mathrm{s} \quad \diamond 14.21 / \mathrm{s}$

\subsection{Inference of heat transfer coefficients from transient conduction analysis}

The results from the cooling of the Perspex brake disc were analysed using the transient conduction analysis described in section 2.1, in a manner similar to [16]. This yields local and spatially averaged heat transfer coefficients for the full range of test parameters, including tests with no jet cooling but variable disc spin speeds. These coefficients are compared with the actual cooling trends reported in the previous section. In addition, the experimentally determined heat transfer coefficients act as boundary conditions for a finite element model of the jet cooled brake disc; this is discussed further in section 4.

For the baseline tests, it was found that the heat transfer coefficients with no applied cooling were substantially lower than the jet cooled coefficients, and varied as expected with disc spin speed. For example, for $H / D$ of 10 , angle of $90^{\circ}$ and spin speed of $1500 \mathrm{rpm}$ the heat transfer coefficient is less than one third of that recorded for the lowest jet flow rate in the same configuration.

From Figure 6 for the average heat transfer coefficients, it can be seen that the effects of air flow rate and dimensionless disc to jet spacing are consistent with the measured cooling times reported in the previous section. Thus, the average heat transfer coefficient rises with decreasing $H / D$ ratio, which is consistent with research by Baydar et al [21]; it was found also to increase with rising air flow rate as anticipated by results of Martin [22]. The trend with angle of impingement is not quite as clearcut; the heat transfer coefficient does increase initially with increasing angle, which is consistent with the trends shown in Figure 4, but the 
heat transfer coefficient appears to reach a plateau rather than peak at $75^{\circ}$. (Geometrical constraints prevented testing at $15^{\circ}$ for $H / D$ of 3.) Although the difference in trend with varying impingement angle may warrant further investigation, the discrepancy is not significant, in the context of the measurement set-up.

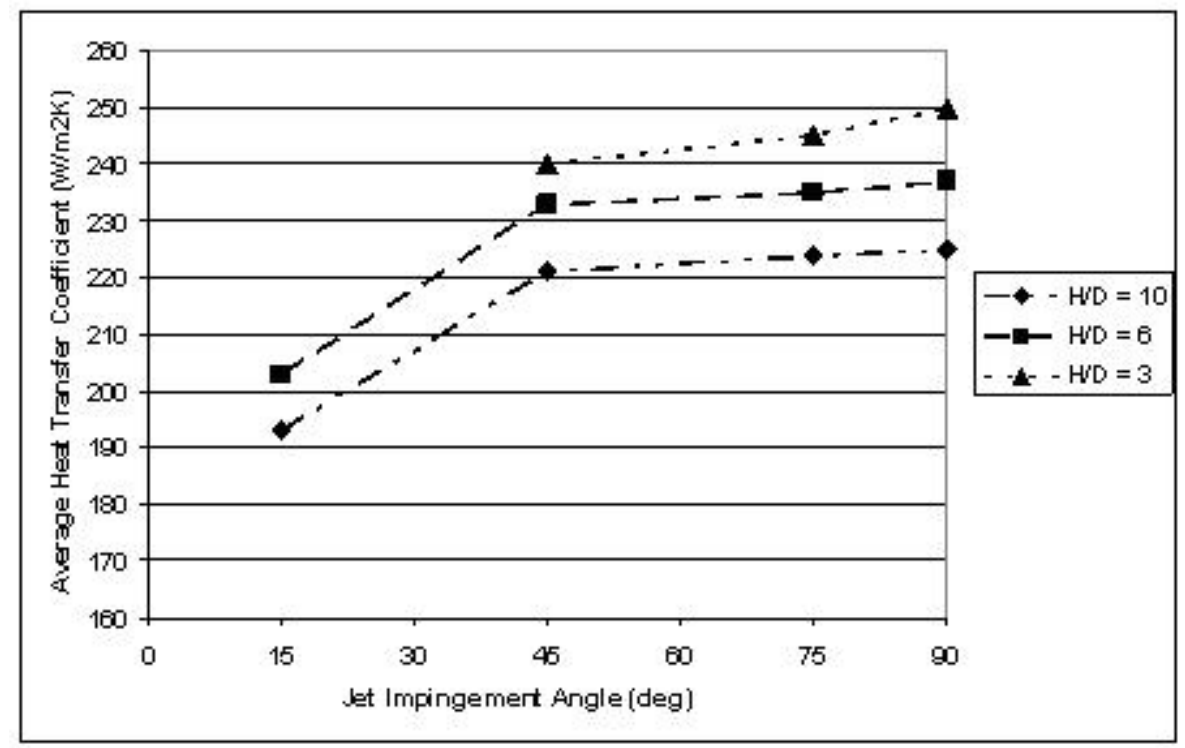

Figure 6 Variation in heat transfer coefficients with $H / D$ and Impingement Angle, $(7.85$ 1/s)

Although average heat transfer coefficients are of practical relevance, local coefficients over the disc flange may provide additional insight into the convective cooling process. Figure 7 shows the radial variation in heat transfer coefficient, superimposed on the actual brake disc, for jet impingement at $H / D$ of 10 , flow rate of $7.851 / \mathrm{s}$ and angle of $90^{\circ}$. Figure 8 shows a more conventional representation of local heat transfer coefficients for a flow rate of $7.85 \mathrm{l} / \mathrm{s}$ and an angle of $90^{\circ}$, for $H / D$ values of 3, 6 and 10 . Two key features stand out. Firstly, for the lowest disc to nozzle spacing, $H / D=3$, secondary peaks in the local heat transfer distribution 


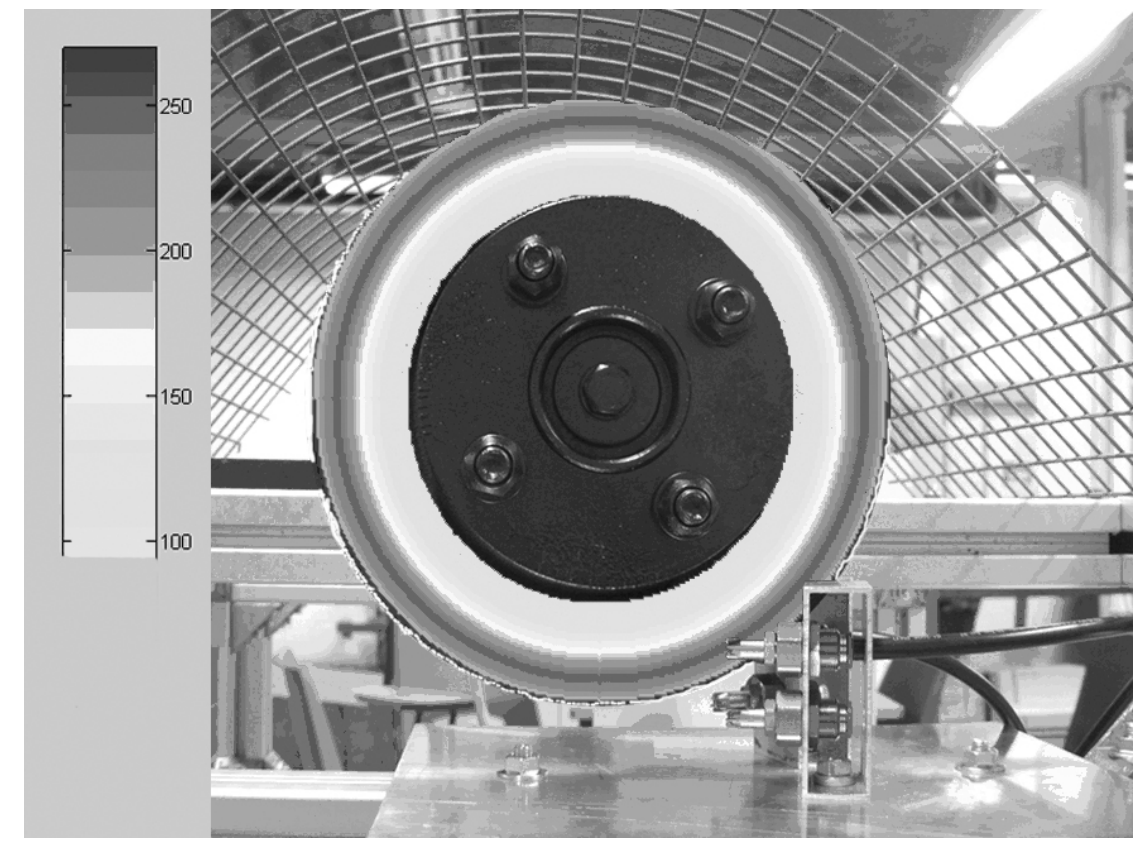

Figure 7 Variation in heat transfer coefficient with radius, superimposed on actual rig

are evident at radial locations of around $r / D=1$ and 2 . In studies by Baughn and Shimizu [23], Huang and El-Genk [24], O’Donovan and Murray [25] and others, secondary peaks in the heat transfer distribution from a stationary surface to an impinging air jet have been reported; in some cases two radial peaks are present in the heat transfer distributions. These peaks have been attributed, in general, to an abrupt increase in turbulence in the wall jet boundary layer [25]. Secondly, in all cases the heat transfer coefficients are highest near the outside edge of the disc. In jet impingement on a stationary, flat surface, normal impingement would be expected to yield symmetry about the jet centre axis. In the current situation, the asymmetry in heat transfer evident in Figure 8 must be due, in large part, to the flow field associated with the spinning brake disc, which would yield higher velocities at the outer edge of the flange. 


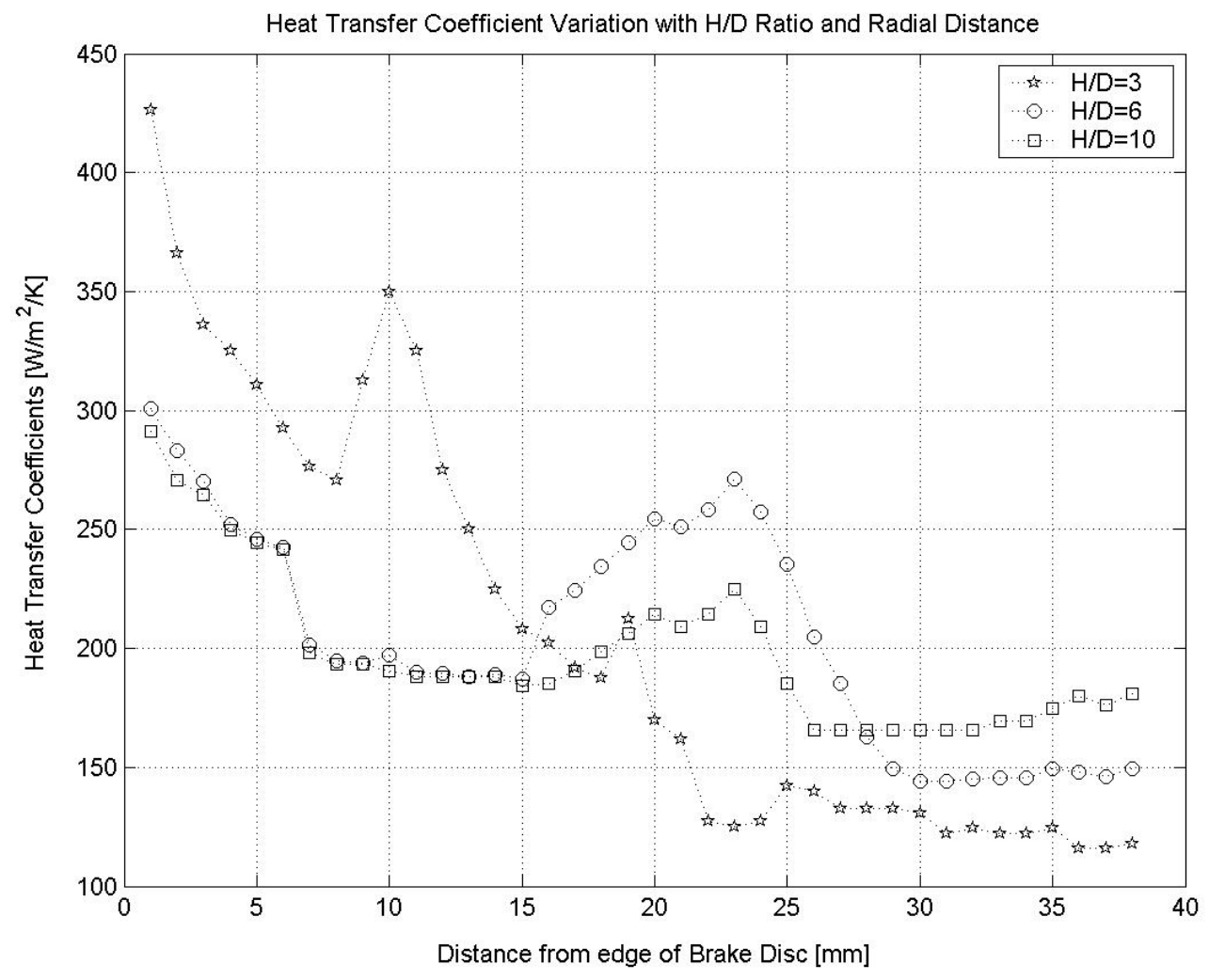

Figure 8 Radial variation in heat transfer coefficient, at different H/D ratios

\section{FINITE ELEMENT MODELLING}

In order to study the likely response of a brake disc to jet cooling after an emergency stop, a finite element model of the disc was developed in ANSYS ${ }^{\circledR}$. The experimentally determined heat transfer coefficients are applied as boundary conditions in the model. The material properties used for the disc, taken from reference [26], are given in table 1 . The element used is the 3-D thermal solid SOLID70, a commonly used element in thermal modeling. A mesh was created and refined using the mesh refine tool until a sufficient degree of accuracy was reached. 


\begin{tabular}{|l|l|}
\hline Thermal conductivity $\mathrm{Wm}^{-1} \mathrm{~K}^{-1}$ & 57 \\
\hline Density $\mathrm{kg} / \mathrm{m}^{3}$ & 7100 \\
\hline Specific heat $\mathrm{J}^{3} \mathrm{~kg}^{-1} \mathrm{~K}^{-1}$ & 452 \\
\hline Coeff. of thermal expansion $\mathrm{K}^{-1}$ & $1.1 \times 10^{-5}$ \\
\hline
\end{tabular}

Table 1. Properties of cast iron

The model was first used to predict the cooling curve of a trial test, where the brake disc was heated to a temperature of $200{ }^{\circ} \mathrm{C}$ and allowed to cool at $1500 \mathrm{rev} / \mathrm{min}$ with no jets. The predicted and measured cooling curves are shown in figure 9. It can be seen that the correspondence between the model and the experimental cooling curve is good, providing confidence in the finite element model.

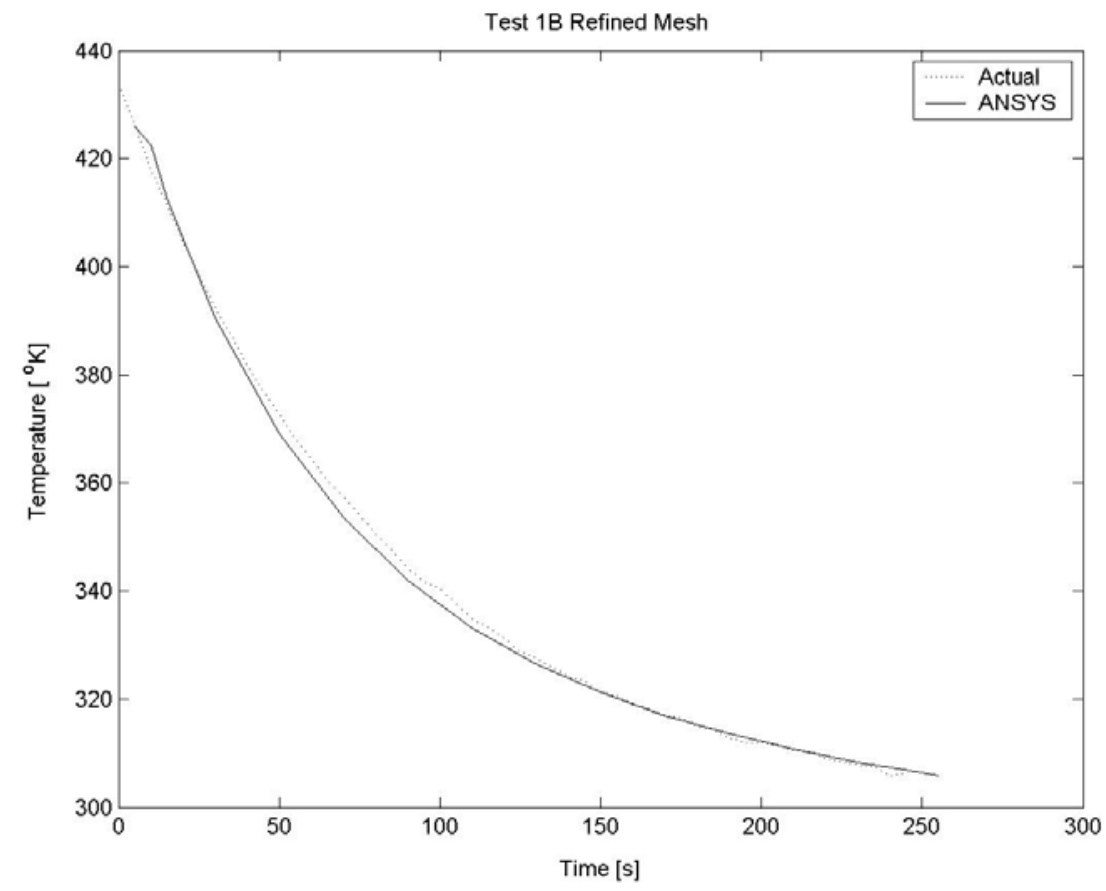

Figure 9 Predicted and measured cooling curves from $200{ }^{\circ} \mathrm{C}$ 
In an emergency stop when most of the kinetic energy of the vehicle is transmitted to the discs as heat, the disc may reach a temperature of $500{ }^{\circ} \mathrm{C}[27,28]$. Figure 10 shows the predicted cooling curves without jets, and with jet cooling at $H / D=3$, flow rate $=7.85 \mathrm{l} / \mathrm{s}$ and impingement angle of $90^{\circ}$. The measured cooling curves from $200{ }^{\circ} \mathrm{C}$, which were shown to mimic that of $160^{\circ} \mathrm{C}$, are superimposed on each predicted curve to show its accuracy. The correspondence between measured and predicted values at lower temperatures is good, which lends more confidence to the higher temperature predictions. It is clear that jet cooling offers scope for removing heat from the brake disc much more rapidly than just the flow induced by the spinning disc, and may thus provide a means of alleviating some of the thermal problems encountered in practical situations.

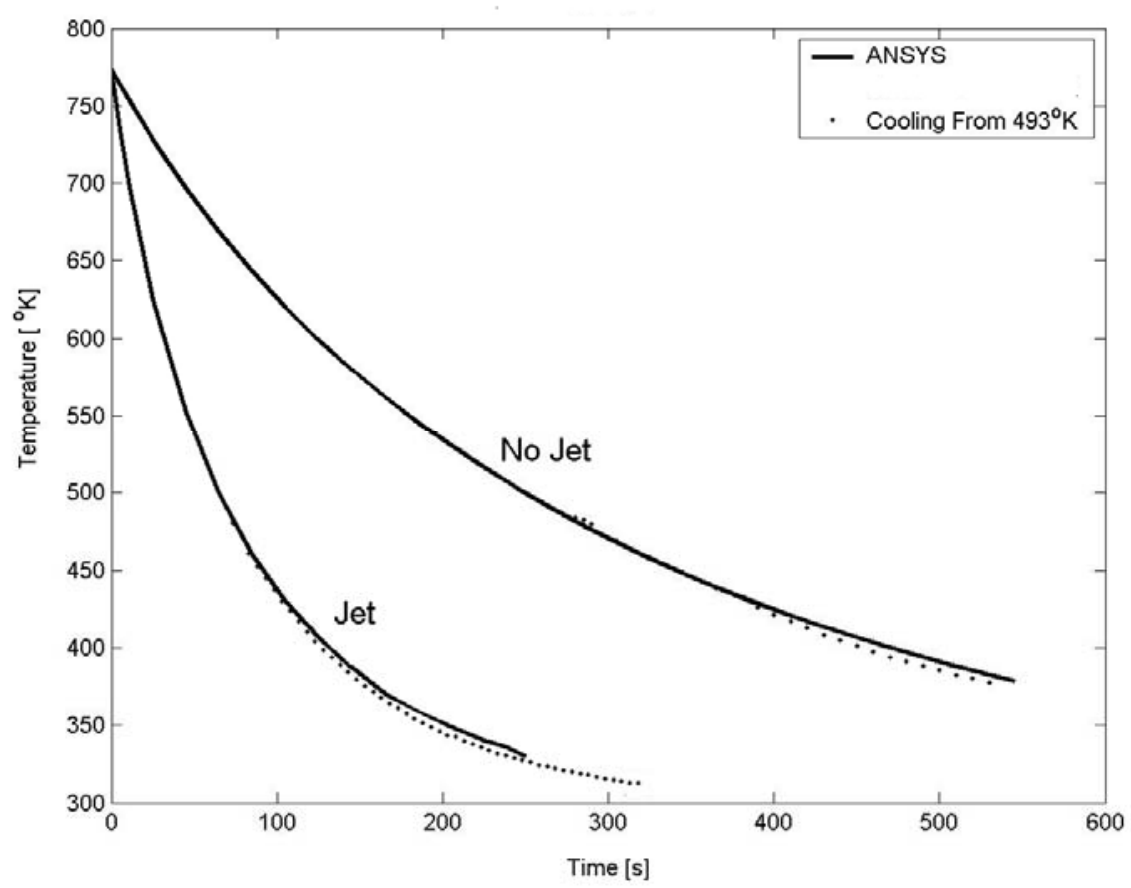

Figure 10 Predicted cooling curves from $500{ }^{\circ} \mathrm{C}$, with and without jets, with measured results superimposed.

\section{DISCUSSION.}


One of the most dangerous conditions in frictional brakes is the formation of macroscopic hot spots (MHS). These occur when the thermal gradients produced in the disc produce stresses high enough to cause yielding. The disc then buckles circumferentially so that all the braking effort is put into the high spots, which then get hotter and hotter [7]. The high convection coefficients which can be achieved with jets may offer a way of alleviating this problem by reducing the thermal gradients in the disc, which are responsible for thermal stress.

We have already shown that the rate of cooling of a brake disc after the application of the brakes is much faster with jet cooling than with natural convection. However, it would also be interesting to see how a higher convection coefficient might influence the heating of the disc during braking itself. The results of the simulated railway braking tests reported by Panier et al. [7], shown in table 2, give almost enough information to allow this to be done, but a few extra assumptions must be made. First, it will be assumed that the maximum braking power is applied continuously during the stop, though clearly it will fall when the vehicle slows sufficiently. Secondly, the material properties of the disc will be assumed to be the same as those of the disc used in our work, and that the thickness of the disc is $80 \mathrm{~mm}$. To obtain an analytical solution of the problem, it will be further assumed that the disc heats uniformly through its thickness when the brakes are applied, an assumption which will tend to underestimate the effect of convective cooling. In reality, the surface temperature will be higher than the bulk temperature of the disc, leading to increased convection for a given mean disc temperature.

\begin{tabular}{|c|r|r|r|r|r|r|r|r|r|}
\hline $\begin{array}{c}\text { Test } \\
\text { no. }\end{array}$ & $\begin{array}{r}\text { Speed } \\
(\mathrm{km} / \mathrm{hr})\end{array}$ & $\begin{array}{c}\text { Disc } \\
\text { OD } \\
(\mathrm{m})\end{array}$ & $\begin{array}{c}\text { Disc } \\
\mathrm{ID}(\mathrm{m})\end{array}$ & $\begin{array}{r}\text { Braking } \\
\text { power } \\
(\mathrm{kW})\end{array}$ & $\begin{array}{c}\text { T max } \\
\left({ }^{\circ} \mathrm{C}\right)\end{array}$ & $\Delta T(K)$ & $\begin{array}{r}\text { Mass } \\
(\mathrm{Kg})\end{array}$ & $\begin{array}{r}\text { Stopping } \\
\text { time }(\mathrm{s})\end{array}$ & $\begin{array}{r}\text { Energy } \\
(\mathrm{MJ})\end{array}$ \\
\hline $\mathbf{1}$ & $\mathbf{6 0}$ & $\mathbf{0 . 6 4}$ & $\mathbf{0 . 3 8}$ & $\mathbf{5 6}$ & $\mathbf{2 6 9}$ & $\mathbf{2 4 4}$ & $\mathbf{3 0 0 0 0}$ & $\mathbf{4 0 3}$ & $\mathbf{1 5}$ \\
\hline $\mathbf{2}$ & $\mathbf{6 0}$ & $\mathbf{0 . 6 4}$ & $\mathbf{0 . 3 8}$ & $\mathbf{5 6}$ & $\mathbf{2 1 1}$ & $\mathbf{1 8 6}$ & $\mathbf{3 0 0 0 0}$ & $\mathbf{2 3 5}$ & $\mathbf{6 . 4}$ \\
\hline
\end{tabular}




\begin{tabular}{|r|r|r|r|r|r|r|r|r|r|}
\hline 3 & $\mathbf{9 0}$ & $\mathbf{0 . 6 4}$ & $\mathbf{0 . 3 8}$ & $\mathbf{8 4}$ & $\mathbf{2 1 4}$ & $\mathbf{1 8 9}$ & $\mathbf{3 0 0 0 0}$ & $\mathbf{2 6 3}$ & $\mathbf{9 . 4}$ \\
\hline 4 & 120 & 0.64 & 0.38 & 164 & 300 & 275 & 27000 & 193 & 15 \\
\hline 5 & 200 & 0.64 & 0.38 & 150 & 300 & 275 & 9800 & 215 & 15 \\
\hline
\end{tabular}

Table 2. Braking test results with estimates of the potential effect of jet cooling.

[The results in bold are for brake applications which initiated MHS

The figures in italic are calculated from the results in this paper]

$\Delta T$ is calculated assuming an ambient temperature of $25^{\circ} \mathrm{C}$

With these assumptions, it is possible to write the following differential equation for the temperature of the disc, $\theta$, as a function of the braking time, $t$, and the initial temperature, $\theta_{0}$

$$
\frac{d \theta}{d t}=\frac{Q-h A\left(\theta-\theta_{0}\right)}{M C}
$$

where $Q$ is the braking power, $h$ the heat transfer coefficient, $A$ the area of the heat transfer surface, $M$ the mass of the disc, and $C$ its specific heat. With a little manipulation, this yields the following solution for the temperature after a braking time $t$.

$$
\theta-\theta_{0}=\frac{Q}{A h}\left(1-e^{\frac{A h}{M C} t}\right)
$$

Using the figures given in table 2 for the first test, we get the predicted heating curves shown in figure 11 . The upper curve assumes $h=60 \mathrm{~W} / \mathrm{m}^{2} / \mathrm{K}$, representing the naturally cooled case, whilst the lower curve assumes $h=300 \mathrm{~W} / \mathrm{m}^{2} / \mathrm{K}$, representing applied jet cooling. Ambient temperature is assumed to be $25{ }^{0} \mathrm{C}$. Where the upper curve reaches the maximum temperature rise measured in the test, the lower curve, representing jet cooling, lies some 50 ${ }^{0} \mathrm{C}$ lower. Smaller reductions were predicted with the other tests, since they are of shorter 
duration, leaving less time for convection to dissipate the heat. Table 3 shows the reduction in temperature predicted for each test at the moment where the maximum recorded temperature is reached.

\begin{tabular}{|c|c|c|c|c|c|}
\hline Test no. & 1 & 2 & 3 & 4 & 5 \\
\hline Predicted fall in temperature $\left({ }^{0} \mathrm{C}\right)$ & 48.8 & 29.7 & 19 & 21.4 & 23.9 \\
\hline
\end{tabular}

Table 3 Predicted reductions in temperature at the maximum with jet cooling

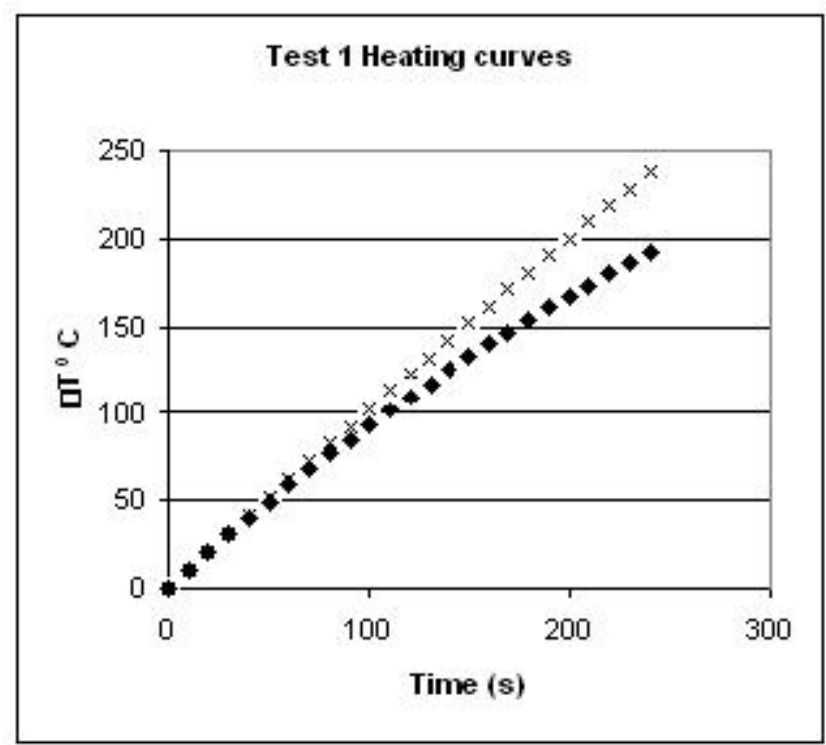

Figure 11 Predicted heating curves for test number 1 . The upper curve assumes natural cooling, and the lower one, applied jet cooling.

The higher convection coefficients achieved with jet cooling will not only reduce the maximum temperature, but will naturally tend to reduce thermal gradients, since heat will be removed faster from hotter parts of the disc. Jet cooling should therefore be very effective in two ways to reduce the risk of MHS formation. A still more powerful effect could be 
achieved by directing the jets so that the local heat transfer coefficients are higher where the hot spots form. This would probably require a control system, since the radius at which hot bands, the precursors of MHS, form varies with time [7].

Another question of interest is the temperature attained by an automotive brake disc during an emergency stop. In this case, if uniform deceleration, $a$, is assumed from in initial velocity $V_{0}$, the differential equation for temperature is modified as follows:

$$
\begin{gathered}
Q=F V=F\left(V_{0}-a t\right) \\
\frac{d \theta}{d t}=\frac{F\left(V_{0}-a t\right)-h A\left(\theta-\theta_{0}\right)}{M C}
\end{gathered}
$$

This equation was solved numerically, piecewise, with a time step of $57 \mathrm{~ms}$ for a vehicle equipped with the brake discs studied in this work. It was assumed that the effective mass braked by each front disc was $500 \mathrm{~kg}$, and that the vehicle decelerated uniformly at $7.848 \mathrm{~m} / \mathrm{s}^{2}(0.8 \mathrm{~g})$ from $160 \mathrm{~km} / \mathrm{hr}$ to rest. Three values of heat transfer coefficient were used, $50 \mathrm{~W} / \mathrm{m}^{2} / \mathrm{K}$, corresponding to natural cooling, $250 \mathrm{~W} / \mathrm{m}^{2} / \mathrm{K}$, and $400 \mathrm{~W} / \mathrm{m}^{2} / \mathrm{K}$; the results are shown in figure 12. The relative reduction in temperature is less than in the longer-lasting railway braking tests, since there is much less time available for convection to remove heat. There could still be the potential for avoiding hot spots, but the advantages are clearly more limited. The maximum temperatures predicted for each heat transfer coefficient are shown in table 4 .

\begin{tabular}{|l|l|l|l|}
\hline $\mathrm{h}$ & 50 & 250 & 400 \\
\hline$\theta_{\max }$ & 561 & 550 & 543 \\
\hline
\end{tabular}

Table 4. Maximum predicted temperatures during an emergency stop for various $\mathrm{H}$ 


\section{Emergency stop}

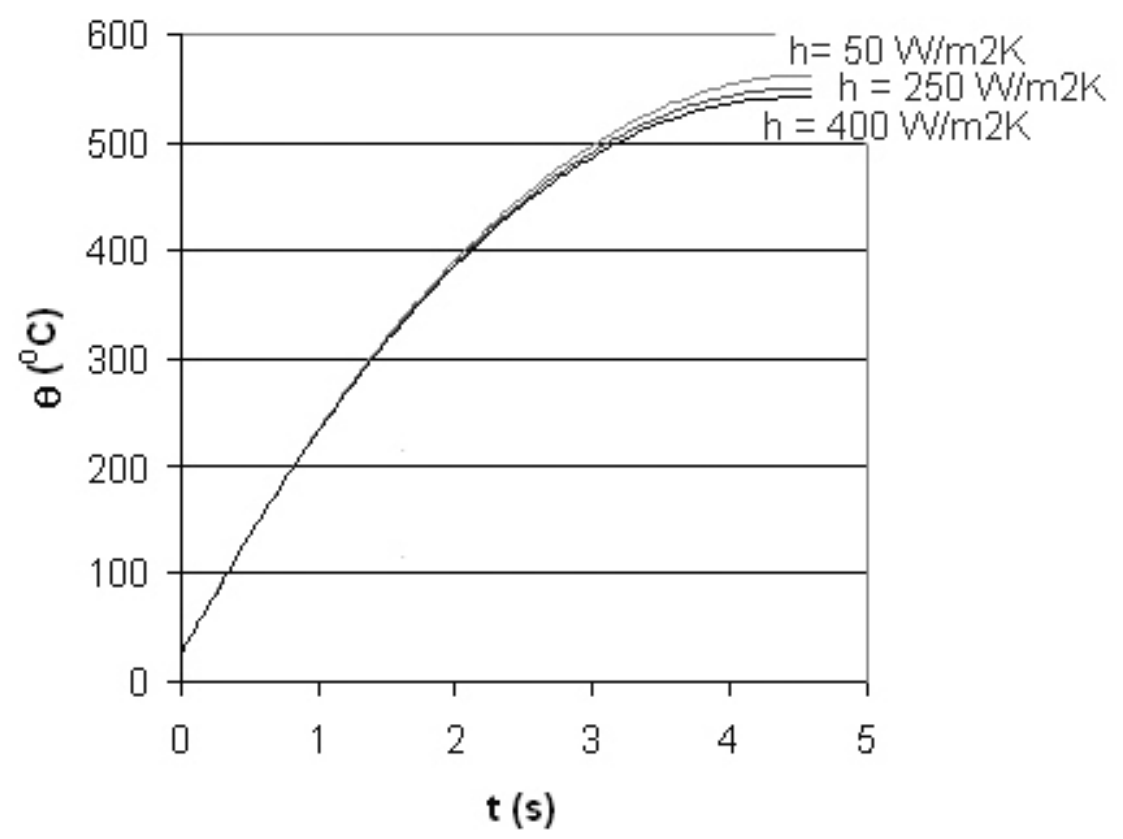

Figure 12 Temperatures predicted during an emergency stop from $160 \mathrm{~km} / \mathrm{hr}$ It would, or course, be possible to enhance convection further by injecting a water mist into the air jet, as we have shown elsewhere [13]. However, there is experimental evidence [29] that this would reduce the coefficient of friction between the brake pads and the disc, leading to a different set of problems.

\section{CONCLUSIONS}

A novel approach to the cooling of brake discs, based on the application of impinging air jets, has been investigated. A test-rig has been designed and constructed to allow brake disc temperature histories to be recorded using IR thermography for varying jet air flow rates, angle of impingement, dimensionless distance from the brake disc and rotational speed. The experimental data obtained have been used to compare the cooling effectiveness of different jet configurations. In addition, the disc temperature histories have been used to estimate convective heat transfer coefficients, using transient conduction analysis; these coefficients 
were subsequently applied as boundary conditions for a finite element model of the process. The results obtained from this investigation suggest that there are benefits to be gained in the long braking cycles used on heavy vehicles. The higher convection coefficients achieved with jet cooling will not only reduce the maximum temperature in the braking cycle but will reduce thermal gradients, since heat will be removed faster from hotter parts of the disc. Jet cooling should therefore be effective to reduce the risk of hot spot formation and associated disc distortion. Implementation would simply require plumbing the nozzles into the vehicle's compressed air supply. For light vehicles, the benefits are less, and implementation is more problematic. Although maximum temperatures may be reduced slightly during short, emergency brake applications, the main benefit of jet cooling in this case will be to restore the disc more rapidly to ambient temperature.

More research is required to optimize the cooling process and determine the engineering cost, in terms of energy and life cycle cost, so as to evaluate it with respect to other thermomechanical options.

\section{ACKNOWLEDGEMENTS}

This research was supported by Science Foundation Ireland, under grant number 04/BRG/E0108.

\section{REFERENCES}

[1] J.J. Santini, F.E. Kennedy, Experimental investigation of surface temperatures and wear in disk brakes, Lubr. Eng. 31 (8) (1975), 402-404, 413-417. 
[2] A.J. Day, T.P.Newcomb, Dissipation of frictional energy from the interface of an annular disc brake, Proc. Inst. Mech. Eng. D: Transp. Eng. 198 (11) (1984) 201-209.

[3] A.A. Evtushenko, E.G. Ivanik, S. Konechny, Determination of the effective heating depth of the disc brake pad, Trenie i Iznosv 19 (3) (1998) 318-322.

[4] K.H. Wollenweber, R. Leiter, Function-monitoring brake system: temperature monitoring brake system, in: Proceedings of the Institution of Mechanical Engineers, International Conference on Braking of Road Vehicles, IMechE, vol. C444/049/93, (1993), pp. 23-48.

[5] J. Bijwe, Nidhi, N. Majumdar, B.K. Satapathy, Influence of modified phenolic resins on the fade and recovery behavior of friction materials, Wear 259 (2005) 1068-1078.

[6] H.S. Qi and A.J. Day, Investigation of disc/pad interface temperatures in friction braking, Wear 262 (2007) 505-513.

[7] S. Panier, P. Dufrénoy and D. Weichert, An experimental investigation of hot spots in railway disc brakes, Wear 256 (2004) 764-773.

[8] M. Boniardi, F. D_Errico, C. Tagliabue, G. Gotti and G. Perricone, Failure analysis of a motorcycle brake disc. Engineering Failure Analysis 13 (2006) 933-945.

[9] M. Kubota, T. Hamabe, Y. Nakazono, M. Fukuda, K. Doi, Development of a lightweight brake disc rotor: a design approach for achieving an optimum thermal, vibration and weight balance. JSAE Review 21 (2000) 349-355.

[10] H.A. El-Sheikh, and S.V. Garimella, Enhancement of air jet impingement heat transfer using pin-fin heat sinks, IEEE Trans. Compon. Packag. Technol., 23 (2000) 300-308.

[11] M. Röger, R. Buck, and H. Müller-Steinhagen, Numerical and experimental investigation of a multiple air jet cooling system for application in a solar thermal receiver, J.Heat Transfer 127 (2005) 863-876.

[12] T. S. O'Donovan, D. B. Murray and A. A. Torrance, Jet heat transfer in the vicinity of a rotating grinding wheel, Proc. I.Mech.E. Part C - J. Mech.Eng.Sci.220 (2006) 837 - 845. 
[13] D. M. Babic, D. B. Murray, A. A. Torrance, Mist jet cooling of grinding processes, International Journal of Machine Tools and Manufacture 45 (2005) 1171 - 1177.

[14] Gillespie D.R.H., Byerley A.R., Ireland P.T. and Kohler S.T., Detailed measurement of local heat transfer coefficients in the entrance to normal and inclined film cooling holes, ASME paper no. 94-GT-1, (1994).

[15] D.B.Murray, B.McMahon and D.Hanley, Local heat transfer coefficients in a finned tubular heat exchanger using liquid crystal thermography, Int.J. Heat Exchangers 1(2000) $31-48$

[16] S.V. Ekkad, S.Ou and R.B. Rivir, A transient infrared thermography method for simultaneous film cooling effectiveness and heat transfer coefficient measurements from a single test, ASME J. Turbomachinery 126 (2004) 597-603.

[17] Martinez-Botas R.F., Lock G.D. and Jones T.V., Heat transfer measurements in an annular cascade of transonic gas turbine blades using the transient liquid crystal technique, ASME paper no. 94-GT-172, (1994).

[18] D.L. Schultz and T.V. Jones, Heat transfer measurements in short duration hypersonic facilities, AGARD report 165 (1973).

[19] Beitelmal Abdlmonem H, Saad Michel A, Patel Chandrakant D, The Effect of Inclination on the Heat Transfer Between a Flat Surface and an Impinging Two Dimensional Air Jet, International Journal of Heat and Fluid Flow, Volume 21, (2000), $156-163$

[20] Subrata Roy, Paresh Patel, Study of Heat Transfer for a Pair of Rectangular Jets Impinging on an Inclined Surface, International Journal of Heat and Mass Transfer, Volume 46, Issue 3, (January 2003), 411-425. 
[21] Baydar E, Ozmen Y, An Experimental And Numerical Investigation on a Confined Impinging Air Jet at High Reynolds Numbers, Applied Thermal Engineering, Volume 25, Issues 2-3, (February 2005), 409-421.

[22] Martin, H., Heat and mass transfer between impinging gas jets and solid surfaces, Advances in heat transfer. Volume 13. New York, Academic Press, Inc., 1977, p. 1-60.

[23] J. W. Baughn, S. S. Shimizu, Heat transfer measurements from a surface with uniform heat flux and an impinging jet, ASME Journal of Heat Transfer 111 (1989) 1096 - 1098.

[24] L. Huang, M. S. El-Genk, Heat transfer of an impinging jet on a flat surface, International Journal of Heat and Mass Transfer 37 (1994) 1915 - 1923.

[25] T. S. O'Donovan, D. B. Murray, Jet impingement heat transfer - part i: Mean and rootmean-square heat transfer and velocity distributions, International Journal of Heat and Mass Transfer 50 (2007) 3291 - 3301.

[26] Choi J. \& Lee I., Finite element analysis of transient thermoelastic behaviours in disk brakes, Wear 257 (2004) 47-58.

[27] Bonairdi M, D’Errico F, Tagliabue C, Gotti G, Perricone G, Failure Analysis of a Motorcycle Disc Brake, Engineering Failure Analysis, Volume 13, (2006), 933-945.

[28] Newcombe T P, Temperatures Reached in Disc Brakes, J. Mechanical Engineering Science, Volume 2, 3, (1960).

[29] P.J. Blau ., J.C. McLaughlin Effects of water films and sliding speed on the frictional behavior of truck disc brake materials Tribology International 36 (2003) 709-715

\section{APPENDICES}

\section{NOMENCLATURE}

\begin{tabular}{|l|l|}
\hline a & Acceleration \\
\hline A & Area $\left[\mathrm{m}^{2}\right]$ \\
\hline
\end{tabular}




\begin{tabular}{|l|l|}
\hline $\mathrm{F}$ & Braking Force \\
\hline $\mathrm{Q}$ & Braking Power $[\mathrm{J}]$ \\
\hline $\mathrm{x}, \mathrm{y}, \mathrm{z}$ & Cartesian Coordinate Variables \\
\hline$\eta$ & Cooling Effectiveness \\
\hline $\mathrm{D}$ & Hydraulic diameter $[\mathrm{m}]$ \\
\hline $\mathrm{h}$ & Local Heat Transfer Coefficient $\left[\mathrm{W} / \mathrm{m}^{2} / \mathrm{K}\right]$ \\
\hline $\mathrm{M}$ & Mass $[\mathrm{kg}]$ \\
\hline $\mathrm{C}$ & Specific Heat Capacity $[\mathrm{J} / \mathrm{kg} / \mathrm{K}]$ \\
\hline $\mathrm{r}$ & Radius $[\mathrm{m}]$ \\
\hline $\mathrm{T}, \theta$ & Temperature $\left[{ }^{\circ} \mathrm{C}\right]$ or $[\mathrm{K}]$ \\
\hline $\mathrm{k}$ & Thermal Conductivity $[\mathrm{W} / \mathrm{m} / \mathrm{K}]$ \\
\hline$\alpha$ & Thermal Diffusivity $\left[\mathrm{m}^{2} / \mathrm{s}\right]$ \\
\hline $\mathrm{t}$ & Time $[\mathrm{s}]$ \\
\hline $\mathrm{t} / \mathrm{s}$ & $\begin{array}{l}\text { Time taken for the surface of the disc to lose half its initial } \\
\text { temperature excess }[\mathrm{s}]\end{array}$ \\
\hline $\mathrm{V}$ & Velocity \\
\hline & \\
\hline Subscripts & \\
\hline 0 & Initial \\
\hline $\mathrm{s}$ & Surface \\
\hline $\mathrm{c}$ & Coolant \\
\hline$\infty$ & Ambient \\
\hline
\end{tabular}

